\title{
Converting to a Capitation System for Dialysis Payment - The Portuguese Experience
}

\author{
Pedro Ponce $^{a}$ Daniele Marcelli ${ }^{b}$ António Guerreiro ${ }^{a}$ Aileen Grassmann ${ }^{b}$ \\ Carlos Gonçalves $^{\mathrm{a}}$ Laura Scatizzi $^{\mathrm{b}}$ Inga Bayh ${ }^{\mathrm{b}}$ Andrea Stopper $^{\mathrm{b}}$ Ricardo Da Silva $^{\mathrm{a}}$ \\ ${ }^{a}$ Fresenius Medical Care, Lisbon, Portugal; ${ }^{\text {b}}$ Fresenius Medical Care, Bad Homburg, Germany
}

\section{Key Words}

Capitation - Bundled payment $\cdot$ Dialysis $\cdot$ Fee-for-service reimbursement $\cdot$ Healthcare management $\cdot$ Quality indicators

\begin{abstract}
Due to the challenge of operating within an economically strained healthcare budget, Portuguese health authorities convened with dialysis providers and agreed on a framework to change from a fee-for-service reimbursement modality to a capitation payment system for hemodialysis. This article reviews the components of the agreed capitation package implemented in 2008 as well as the necessary preparatory work undertaken by a for-profit 34-unit dialysis network (approx. 4,200 patients) to cope with the introduction of this system. Furthermore, trends in clinical quality indicators and in resource management are reviewed for 3 years immediately following capitation introduction. Here, improvements were observed over time for the specified clinical targets. Simultaneously, costs controllable by the physician could be reduced. As more countries convert to a capitation or bundled payment system for hemodialysis services, this article offers insight into the scope of the necessary preparatory work and the possible consequences in terms of costs and treatment quality.

Copyright $\odot 2013$ S. Karger AG, Basel
\end{abstract}

\section{Introduction}

The projected growth in spending for the treatment of end-stage renal failure threatens to become unsustainable for most countries. According to recent analyses, the greatest potential for cost savings in healthcare is a payment approach that includes a blend of the following: budget-based total or partial capitation; a robust structure of electronic medical records; a pay-for-performance (P4P) system to compensate physicians, and effectiveness review bodies that analyze future medical advances and decide what should be covered or included in the care process [1, 2]. In 2008, the Portuguese Ministry of Health $(\mathrm{MoH})$, concerned with budget constraints and the exponential rise of dialysis cost, reached an agreement with the Portuguese association of dialysis providers (Anadial) to change the reimbursement system according to these principles, transitioning from a 'fee-for-service' reimbursement to a capitation system [3]. Capitation is a prospective payment system in which the dialysis treatment providers receive, upfront, a predetermined a mount of money per capita to cover specified services for a defined time period [4-6]. The agreed capitation system was implemented in April 2008 and applies only to the provision of hemodialysis; peritoneal dialysis and transplant patients are treated exclusively in public hospitals in

\section{KARGER}

Fax +41613061234

E-Mail karger@karger.ch

www.karger.com (c) 2013 S. Karger AG, Basel

0253-5068/12/0344-0313\$38.00/0

Accessible online at:

www.karger.com/bpu
Dr. Pedro Ponce

Rua Professor Salazar de Sousa, Lote 12

PT-1750-233 Lisboa (Portugal)

E-Mail pedro.ponce@fmc-ag.com 
Table 1. Hemodialysis clinical quality indicators negotiated with the Portuguese $\mathrm{MoH}$

Clinical quality indicators

\begin{tabular}{l|l}
\hline Process indicators & Outcome indicators \\
\hline $\begin{array}{l}\mathrm{eKt} / \mathrm{V} \geq 1.2 \text { in }>75 \% \text { of all patients } \\
\% \text { of patients treated thrice weekly }>90 \%\end{array}$ & $\begin{array}{l}<1 \text { hospital admission/patient-year } \\
\text { Annual mortality } \leq 20 \%\end{array}$ \\
$\mathrm{t} \geq 12 \mathrm{~h} /$ week in $>90 \%$ of all patients \\
$\begin{array}{l}\text { Hemoglobin } \geq 10 \mathrm{~g} / \mathrm{dl} \text { and } \leq 13 \mathrm{~g} / \mathrm{dl} \text { in } \geq 70 \% \text { of all patients } \\
\text { Ferritin } \geq 200 \text { and } \leq 800 \mathrm{ng} / \mathrm{ml} \text { in } \geq 80 \% \text { of all patients } \\
\begin{array}{l}\text { Phosphate } \geq 3.5 \text { and } \leq 5.5 \mathrm{mg} / \mathrm{dl} \text { in } \geq 50 \% \text { of all patients } \\
\% \text { water quality tests that comply with guidelines } \geq 90 \%\end{array}\end{array}$ \\
$\begin{array}{l}\text { Possible future process indicator: } \\
\text { Albumin } \geq 4 \mathrm{~g} / \mathrm{dl} \text { in } \geq 60 \% \text { of all patients }\end{array}$ & $\begin{array}{l}\text { Possible future outcome indicator: } \\
\leq 15 \text { days hospitalized/patient-year }\end{array}$ \\
\hline
\end{tabular}

Portugal and, to date, no capitation agreement for these modalities has been developed.

Presently, in Portugal, the dialysis treatment market is predominantly served by two large for-profit dialysis networks. As one of these dialysis networks, treating approximately 4,200 patients in 34 dialysis units (comprising almost $50 \%$ of the dialysis patient population in Portugal), NephroCare Portugal had to critically review its operation and change procedures at all levels in order to meet the challenges posed by the introduction of capitation payment. The aim of this paper is to review (1) the components of the Portuguese capitation package including changes made thereto since its introduction, (2) the nature and extent of the preparatory work necessary to prepare a dialysis network for a switch to capitation reimbursement, and (3) the changes in the quality and cost of dialysis care provided by the network in the years immediately following capitation introduction.

\section{Description of the Capitation Package}

The agreement between Anadial and the $\mathrm{MoH}$ was the result of many in-depth discussions that culminated not only in an agreed price tag for bundled services and an agreement on which services are included, but also specified particular quality-of-care targets and methods to demonstrate that these quality targets were achieved. Consequently, hemodialysis providers receive a fixed payment for each patient per week and, in return, provide dialysis-related services within this budget. Specifically, the following services are bundled together in the capitation budget: (1) dialysis treatment; (2) laboratory and imaging tests; (3) all medication for the treatment of anemia, bone mineral disease, nutrition and cardiovascular comorbidities; (4) intradialytic intravenous antibiotics, and, since 2011, (5) vascular access (VA) management [7]. Patient transportation and hospitalization costs are presently not included in the package. The corresponding prospective package payment per week was EUR 547.94 in 2010 but, due to the national financial crisis, this was reduced to EUR 537.25 in 2011 despite adding the service of VA management [8]. According to a recent comparison of dialysis reimbursement of seven countries, this weekly package payment is roughly comparable to that in the US, but considerably lower than that in other European countries [9].

The quality of services provided is monitored according to a list of 'clinical quality indicators'. With the exception of VA management, these comprise various 'process indicators' and 'outcome indicators' (table 1). Process indicators are defined as goals related to the dose of dialysis, control of anemia and renal osteodystrophy, as well as the management of dialysis water quality. Outcome indicators relate to morbidity (represented by the number of hospitalizations per patient-year) and annual crude mortality rate. All indicators reflect national and international best practice guidelines for patients undergoing hemodialysis. To date, no official clinical quality indicators exist for monitoring VA; in order to bridge this gap, ten potential indicators have been proactively proposed by NephroCare Portugal (described later).

To receive payment, the targets for the clinical quality indicators (table 1) must, by law, be met by all dialysis units of the dialysis network. Failure to do so is first followed by warnings from the $\mathrm{MoH}$ and later by penalties ranging from suspension of payment to even withdrawal of clinic licences. All relevant information to enable qual- 
ity control is to be automatically transferred through an interface between the network's database and an official IT platform managed by the MoH. Organization of the infrastructure necessary to facilitate this lies in the responsibility of the dialysis provider, who shoulders all the associated costs.

\section{Preparation for Capitation Payment Introduction}

The action plan devised by NephroCare Portugal to prepare itself for the introduction of capitation payment comprised, in essence, four necessary actions and one additional action addressing VA, the need for which was already predictable in 2008 .

\section{Review of Current Practices}

To begin, current practices within the network were reviewed with the aim to identify strategies that could improve overall cost efficiency. Special focus was placed on the specific clinical quality indicators required. Various promising strategies based on common practices were identified and subsequently followed in many clinics. These included the following:

- critical examination of the rationale behind prescriptions of over 3 treatments per week, large surface area dialyzers and/or a dialysate flow in excess of $500 \mathrm{ml} /$ min, as comparable performance may be attainable with other measures, such as higher blood flows and/ or greater compliance to prescribed treatment time;

- close evaluation and adjustment of the dry weight, due to the potential to reduce morbidity and mortality as well as due to the need for antihypertensive medication;

- implementation of a proactive program for registration and prevention of bacterial infection, one of the root causes of morbidity and mortality;

- closer adherence to 'fistula first' and 'catheters last' due to the potential to significantly reduce infectionbased morbidity and mortality, VA center procedures and, consequently, operative dialysis costs;

- improvement in dietician support to reduce sodium and phosphorus intake;

- optimization of intravenous iron therapy due to the potential to reduce erythropoiesis-stimulating agent consumption;

- critical assessment of protocols for routine diagnostic tests, as the cost of routine laboratory work was observed to be over $150 \%$ higher in the most expensive units compared to the least expensive units.

\section{Design of an Internal P4P System}

It was decided to avoid negative financial incentives and rather focus on a positive incentive scheme. The final system embraces three different performance domains resource management, clinical performance and patient satisfaction - whereby each domain was given a different weighting regarding the awarding of the overall financial incentive payment.

Resource Management (50\% of Incentive Payment). Based on records from 2006 and 2007, a minimum to maximum cost range was defined per dialysis for the sum of the following 3 cost items: (1) dialysis prescription (namely, times per week, filter area, dialysate flow, anticoagulation strategy, and others); (2) pharmaceuticals, and (3) diagnostic tests (laboratory and imaging tests). A unit with average total costs close to the minimum will receive a maximum incentive bonus, and a unit with average total costs close to the maximum will not receive any incentive payment. Importantly, there are no incentives for targeting average costs below the minimum of the range.

Clinical Performance (40\% of Incentive Payment). As reaching a 'goal' in the clinical quality indicators could inhibit continuous improvement, the incentive system was designed to reward improvement above the established 'official' targets. 'Improvement above targets' was measured as follows: (1) a higher than targeted proportion of patients with adequate hemoglobin levels; (2) a higher than targeted proportion of patients with adequate mid-week predialysis phosphate levels; (3) a higher than targeted proportion of patients with $\mathrm{eKt} / \mathrm{V}>1.2$ and a treatment time of $12 \mathrm{~h}$ /week; (4) a lower than targeted crude mortality rate, and (5) a lower than targeted number of hospital admissions per patient-year. A clinical score was created on the basis of these five criteria: this is calculated as the number of percentage points above the target values in (1) + (2) + (3) - 2 points for each percentage of mortality above $16 \%-1$ point for each 0.1 admissions per patient-year above 0.7. Regardless of their absolute clinical score, the 2 units reporting the highest improvement compared to the previous year receive the full incentive payment allotted to this domain.

Patient Satisfaction (10\% of Incentive Payment). Payment is awarded in proportion (sliding scale) to the percentage of patient satisfaction, as evaluated using the network's recognized, standardized and validated Patient Satisfaction Questionnaire [10]. No incentive payment is given for rates below $50 \%$, and full payment is awarded for levels above $75 \%$. 


\section{Creation of an Internal Audit and Alert System}

An internal audit system was created to continuously monitor the performance of each unit and thereby identify units that underperform. This system should help physicians from underperforming clinics to develop plans to enhance their performance up to at least the average performance level in the network. The internal audit system is monitored by the Country Medical Director every 6 months. Alarm thresholds were specified as follows, in relationship to the $\mathrm{P} 4 \mathrm{P}$ criteria previously described.

Resource Management. An alert is signaled whenever a unit performs as one of the 3 most expensive units of our network in the last 6 months, for any 3 out of the past 6 months.

Clinical Performance. In each 6-month period, clinics are identified that do not reach at least 2 official clinical quality indicators for 3 consecutive months. In addition, the 3 units that, in the same period, presented the lowest performance of the network in at least 3 months are identified. The relevant clinical quality indicators are the following: (1) proportion of patients within the hemoglobin target range; (2) proportion of patients with predialysis phosphate in the target range, and (3) proportion of patients with $\mathrm{eKt} / \mathrm{V}>1.2$. An alarm is also signaled if the established targets for mortality or morbidity are not met for 2 consecutive years.

Patient Satisfaction. The 3 units are identified that rank last in the patient satisfaction survey rates for 2 consecutive surveys (conducted every 2 years).

If an alarm situation is detected, the Country Medical Director contacts the Clinic Medical Director asking for interpretation of the results and a correction action plan. The Country Medical Director may offer support in the preparation/revision of this correction plan. All clinical quality indicators are reported monthly to all the NephroCare Clinics, making the full process transparent and empowering the Clinic Medical Directors to promptly detect possible problems and to make amends in a timely fashion, thus preventing cases of noncompliance with the clinical quality indicators stipulated by the healthcare authorities and the related consequences. Each unit receives two tables summarizing adherence to the clinical quality indicators, one providing monthly average results for the whole of the Portuguese network, and one with the same information for that specific clinic. In addition, in order to support efforts to enhance efficiency, graphs providing feedback on the costs induced by the prescription of pharmaceuticals, laboratory work and imaging studies are sent to each unit. An example of such a graph sent to a clinic at the end of September is provided in figure 1 .

\section{$I V$. Provision of Easy-to-Interpret Reports to the $\mathrm{MoH}$}

The final necessary activity in the action plan was the upgrading of the network's database and clinical management IT tools in order to meet the new requirements on data gathering, analyses and transmission, and thus, enable the $\mathrm{MoH}$ to easily inspect performances. The NephroCare network database $\mathrm{EuCliD}^{\odot}$ [11] was upgraded accordingly and now automatically transfers all relevant patient data to an official Integrated Management Information System for chronic kidney disease in the $\mathrm{MoH}$.

V. Preparation for Expanding the Package to Include VA VA was included in the capitation package only in 2011, but was already foreseen in 2008, at the time of introduction of capitation in Portugal. Therefore, preparatory work for this development was made part of the action plan for capitation implementation preparation. Based on experience gathered over some years by the Portuguese NephroCare network, which already operated one Surgical Vascular Access Centre (VAC), focus was placed on the following actions: (1) forecast of the number of referrals obtainable from the network's own dialysis units in the area covered by this VAC; (2) analysis of clinical indications for referral to surgery and/or endovascular treatment; (3) coding for all techniques performed in both poles of the VAC; (4) definition of clinical quality indicators for the VAC performance and for the dialysis unit (table 2); (5) development of payment rules for surgeons and intervention nephrologists indexed to results (table 2), and (6) development of a robust IT tool for electronic ordering and scheduling of procedures by the dialysis unit to the VAC, issuing of procedure reports back to the unit, results auditing and management. A pilot VAC was created with the aim to be later replicated in other parts of the country. This was structured as an ambulatory surgical unit operating continuously from 9.00 to $21.00 \mathrm{~h}, 5$ days a week, and having an operating room and an angiography suit. It was staffed by 5 surgeons and 5 teams of intervention nephrologists having as their mission: (1) to facilitate access to an experienced VA surgeon or intervention nephrologist in less than $24 \mathrm{~h}$; (2) to increase the number of prevalent patients dialyzed with a native AV fistula (AVF), and (3) most importantly, to reduce the number of patients requiring a catheter as a VA. Procedures performed in the VAC included: (1) surgical creation or revision of native AVF and polytetra- 


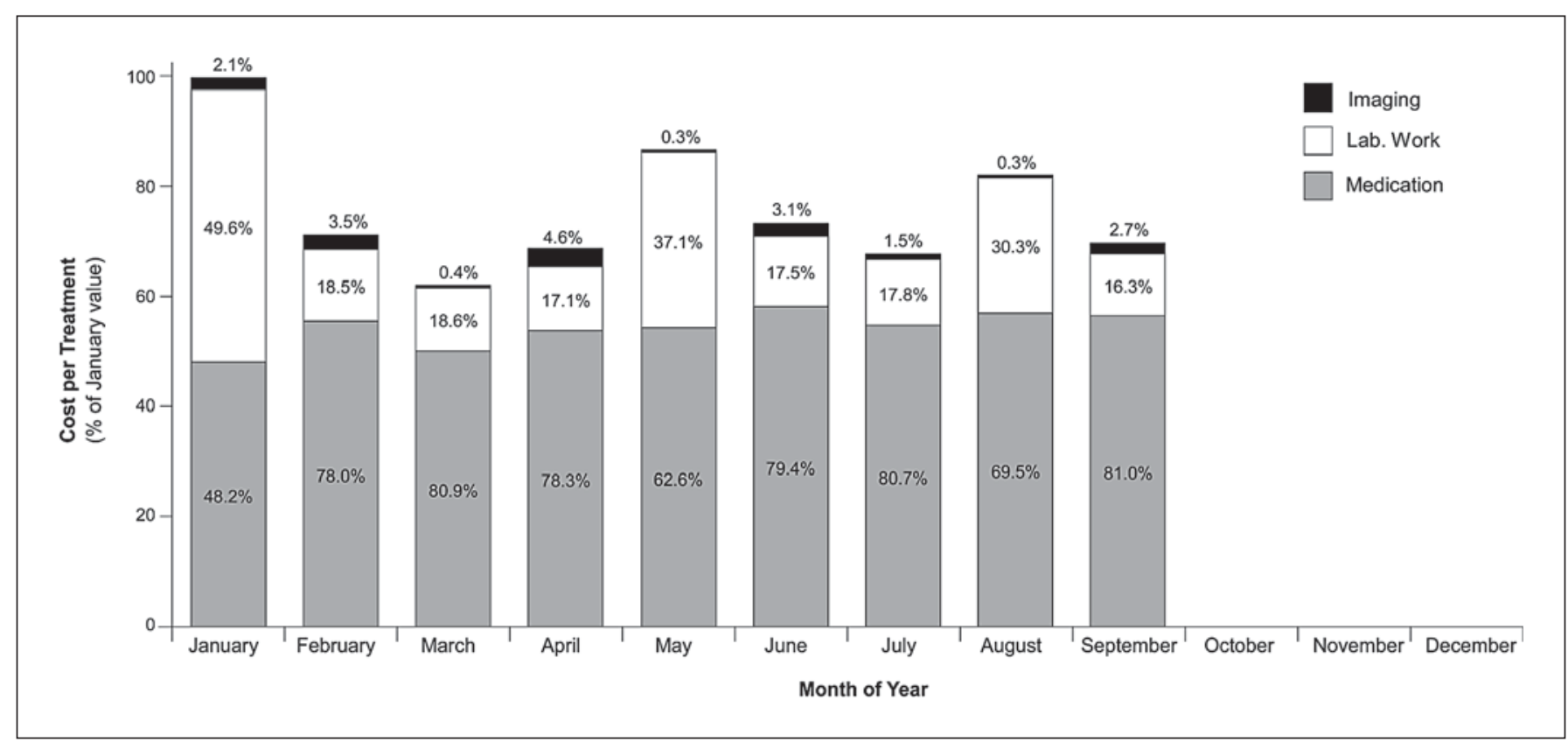

Fig. 1. Example of the cost information provided to each clinic in the network on a monthly basis as part of the internal audit system. The cost for routine laboratory tests varies according to the calendar profile used (monthly, 3-monthly or yearly profile). In this example, the annual tests were done in January 2011.

Table 2. Clinical quality indicators and physician fee regulations for VA management as proposed by NephroCare for inclusion in the dialysis capitation package from 2011

Clinical quality indicators for the VA:

a A successfully usable native AVF as first VA in $80 \%$ of all patients

b A successfully usable native AVF as second VA in $60 \%$ of all patients

c $\%$ of native AVF with primary failure at 3 months $<40 \%$

d $\%$ of PTFE grafts with primary failure at 3 months $<30 \%$

e $\%$ of patent VA post-thrombolysis at 7 days $>75 \%$, at 3 months $>50 \%$

f $\%$ of PTAs that increased access flow more than $40 \%,>75 \%$

g Absence of VA infection at 15 days after intervention in the VAC $>95 \%$

Clinical quality indicators for the dialysis unit:

a Prevalent patients with a native fistula $>65 \%$

b Prevalent patients with a tunneled catheter $<20 \%$

c Referrals to the $\mathrm{VAC}<1$ per patient-year

Physician fee regulations:

1 Procedure fees are a combination of a fixed part and a variable portion which is dependent on the quality of the results obtained; for a PTFE, a surgeon receives the same amount paid for native AVF

2 The variable part of the payment for a new or revised VA is only paid when the access allows 3 consecutive adequate dialyses $(\mathrm{Kt} / \mathrm{V}>1.2)$ with a blood flow $>300 \mathrm{ml} / \mathrm{min}$ during a period of 3 months after surgery

3 Diagnostic angiographies without intervention are compensated with only the fixed part of the payment

4 Only angioplasties that result in an increase in Kt/V of $20 \%$ or an increase of $50 \%$ in the access flow within 1 month will receive the variable part of the composite payment

5 The variable payment for thrombolysis will only be paid if the VA remains patent after 30 days

$\mathrm{VA}=$ Vascular access; PTA = percutaneous transluminal angioplasty; $\mathrm{VAC}=$ vascular access center. 
fluoroethylene (PTFE) grafts; (2) vein transpositions; (3) surgical treatment of VA limb ischemia; (4) surgical treatment of VA infection or aneurysms; (5) diagnostic angiography; (6) percutaneous angioplasty with or without stenting; (7) pharmacological/mechanical thrombolysis, and (8) vascular mapping by Doppler ultrasound or angiography.

According to the model developed, an average cost of EUR 1,200/patient-year was estimated for the management of VA. Assumptions, based on previous experience, were (1) a VA prevalence of $70 \%$ for native AVF, $15 \%$ for PTFE grafts and 15\% for catheters; (2) an average half-life of 3 years for native AVF, 1.5 years for PTFE grafts and 6 months for catheters, and (3) 40,70 and $100 \%$ of all AVF, PTFE grafts and catheters, respectively, will need an intervention each year.

\section{Quality and Efficiency Changes after Capitation Introduction}

To evaluate quality and efficiency changes as recorded in the scope of reporting performances to the Portuguese $\mathrm{MoH}$ following the switch to capitation payment, a review of all 34 Portuguese NephroCare clinics was conducted for the time period from January 2008 to December 2010. In April 2008, the date of introduction of capitation payment in Portugal, these clinics were treating around 4,000 patients. EuCliD data were analyzed that form the basis of the monthly $\mathrm{MoH}$ reports produced by the network. The monthly $\mathrm{MoH}$ reports include the average percent value reached by each clinic and by the sum of all clinics in the network for the seven process indicators and for the 2 outcome indicators (table 1). In order to facilitate identification of time trends, monthly fluctuations were suppressed by averaging the information on a quarter-yearly basis. The results are portrayed as boxplots, performed using SAS 9.2, where the bottom and top of the box are the 25th and 75th percentile, the band represents the median, the star is the mean value, and the ends of the whiskers represent the lowest observation still within the 1.5 interquartile range of the lower quartile and the highest observation still within the 1.5 interquartile range of the upper quartile. Outliers are indicated as small squares.

Figure 2 shows the number of targets reached by the complete network on average from the quarter before capitation introduction (i.e. Q1, 2008) up until the end of 2010. As the data recording tools developed in preparation for capitation introduction were completed just before capitation introduction, a baseline period longer than Q1 2008 was not possible. The maximum possible number of targets is 9 , as defined in table 1 . The number of targets reached clearly increases over time, with a parallel decrease in variability. More detailed results pertaining to the process indicators are presented in figure 3. For example, eKt/V exhibits a positive trend after start of capitation payment, and the mean value is nearly always above the target of $75 \%$ of patients having an eKt $/ \mathrm{V}$ $\geq 1$. . Dialysis time also improves continuously after capitation: the mean value is always above $90 \%$ for the percentage of patients receiving at least thrice weekly dialysis and is nearly always above $90 \%$ for the percentage of patients having a weekly dialysis treatment time of $\geq 12 \mathrm{~h}$. Also, the mean of hemoglobin and phosphorus reach their targets of 70 and $50 \%$, respectively, of patients with levels in the targeted ranges. Ferritin is the only parameter which does not reach the target of $80 \%$; on average, only $72 \%$ of all patients have ferritin values in the required range of 200 to $800 \mathrm{ng} / \mathrm{ml}$. Details of the trends in outcome indicators are depicted in figure 4 . The targets for the hospitalization rate (i.e. $<1$ hospital admission per patient-year) as well as for mortality (i.e. annual mortality $\leq 20 \%$ ) are generally achieved by all Portuguese NephroCare clinics.

In addition to targeting quality increases, as represented by the clinical quality indicators, the cost aspect of providing dialysis is also of major interest. Figure 5 depicts the average monthly pharmaceutical costs per treatment for all Portuguese NephroCare clinics from April 2008 to December 2010. The maximum of costs, which were reported in June 2008 , is defined as $100 \%$, and all other costs are calculated in relation to this value. During this observation period, averaged monthly pharmaceutical costs fell by around $31 \%$. Analysis of the same costs over a longer time period, i.e. up to April 2011 (data not shown), revealed a comparable cost saving of $29 \%$, as well as a better standardization of care, as indicated by a reduction in cost variability. Similarly, laboratory cost savings of $21 \%$ could be achieved by 2011 , and significant investments made by the network since 2008 in dialysis equipment could be almost balanced out by prescription cost savings on dialyzers (1.4\%), dialysis fluid (5.4\%) and anticoagulants (4.5\%). The overall cost-effectiveness of capitation can be expressed as the change in the total cost of care per patient and defined as the provider capitation payment plus the cost of VA plus the hospitalization cost. According to this calculation, the annual cost of dialysis care in the Portuguese non-public sector was around EUR 33,500 in 2009, increased to EUR 35,000 in 2010 
Fig. 2. Number of targets reached for all Portuguese NephroCare clinics on average for the 9 clinical quality indicators listed in table 1 . The diagonally striped bar indicates the baseline, i.e. the time before the introduction of capitation payment. Median values are connected.

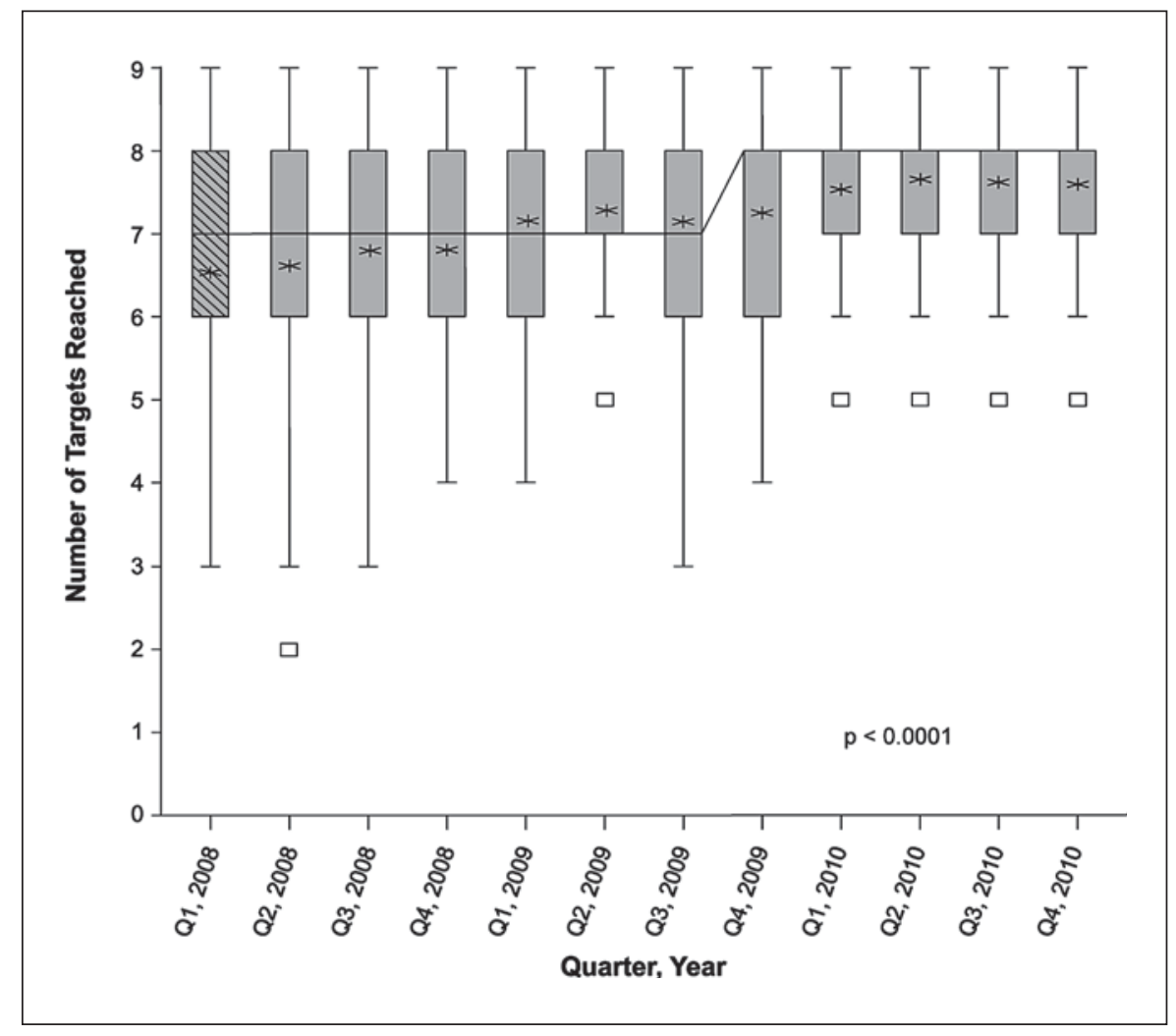

(due to a peak in the number of hospital days) and fell to EUR 30,000 at the end of 2011. Without taking inflation into account, this 2009-2011 change in a capitation environment constituted a cost of care saving of $10.5 \%$.

\section{Discussion and Conclusion}

In 2008, reimbursement for the provision of hemodialysis treatment in Portugal was changed from a fee-forservice modality [12] to a capitation system. Such payment systems are of significant interest to many National Health Care authorities, especially those struggling with acute economical crises. In January 2011, a bundled payment system was introduced in the US for dialysis provision, and its impact after 1 year was recently reviewed [13]. Here, the components of the capitation package introduced in Portugal are described. In addition, the programs devised by a major dialysis clinic network to prepare for the shift from fee-for-service reimbursement to capitation payment are reviewed, and the subsequent changes in quality and cost of care in the clinics are described.

Converting to a Capitation System for

Dialysis Payment
A retrospective analysis of trends in reported target achievements between January 2008 and December 2011 revealed a clear improvement in clinical outcomes coupled with cost reduction. In fact, already in the third year of application of the capitation reimbursement policy in Portugal, the average levels of the clinical quality indicators were in the targeted ranges. The only exception was ferritin, where levels between 200 and $800 \mathrm{ng} / \mathrm{ml}$ were reached in $72 \%$ of all patients, rather that the targeted $\geq 80 \%$. The validity of this parameter as a reliable anemia indicator is presently under discussion in nephrology circles. As the clinical quality indicators (table 1) were defined and introduced only shortly before the actual introduction of capitation payment, it is not possible to clearly differentiate between trends which reflect a continuous process that started before 2008 and trends which reflect actual responses to capitation introduction. Nevertheless, the fact that an improvement in all key clinical quality indicators was observed indicates that quality of care standards did not decrease following capitation payment introduction.

The successful attainment of targets was certainly facilitated by the development of an intensive adaptation 


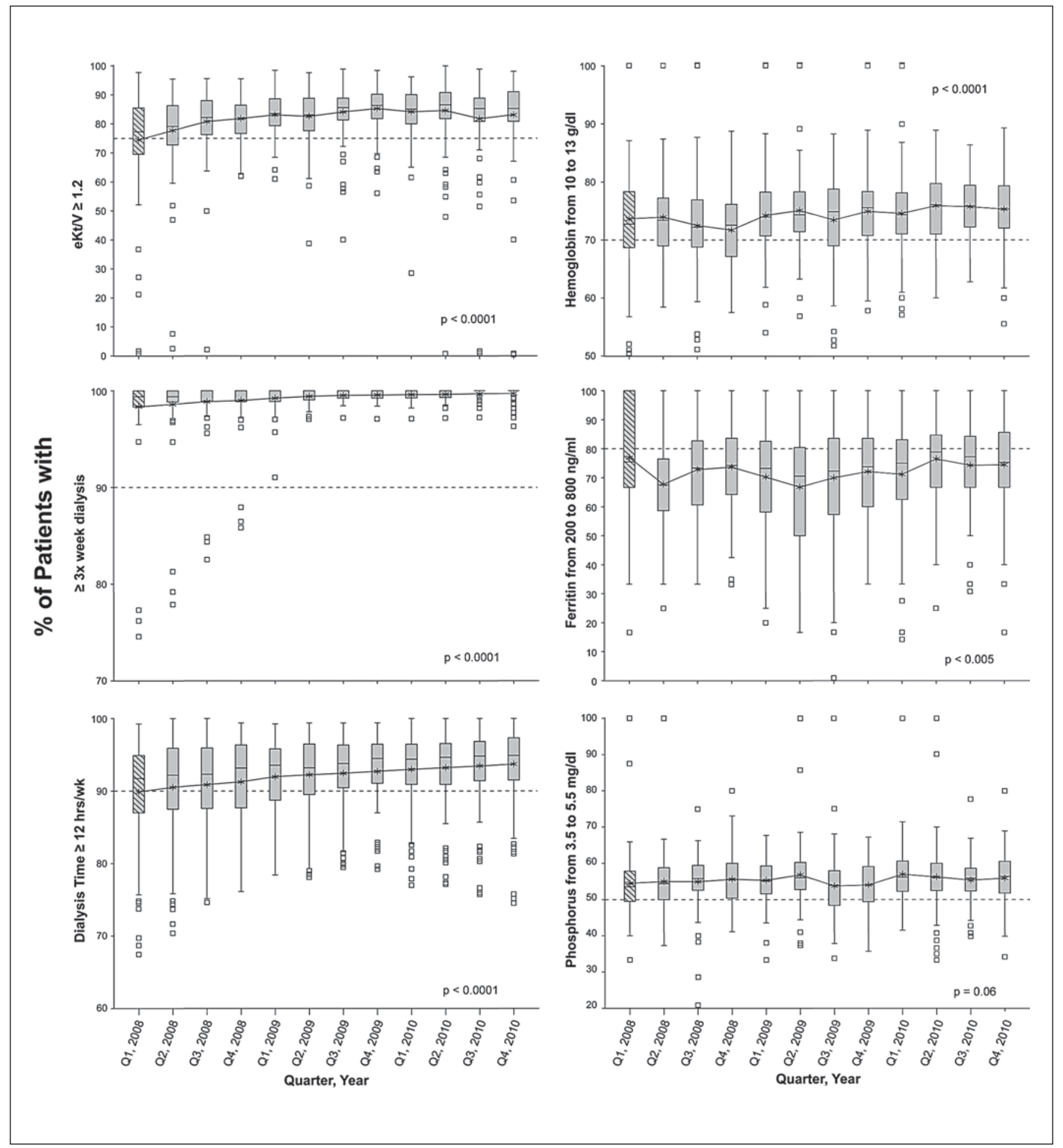

Fig. 3. Quarter-yearly values for 8 of the 9 process indicators listed in table 1 . Results for water quality indicator were consistently $100 \%$ and are therefore not shown. The diagonally striped bar indicates the baseline, i.e. the time before the introduction of capitation payment. The horizontal dashed line indicates the reference value for each parameter. Mean values are connected by a line. 
Fig. 4. Quarter-yearly values for the 2 outcome indicators listed in table 1 . The diagonally striped bar indicates the baseline, i.e. the time before the introduction of capitation payment. The horizontal dashed line indicates the reference value for each parameter. n.s. $=$ Not significant.

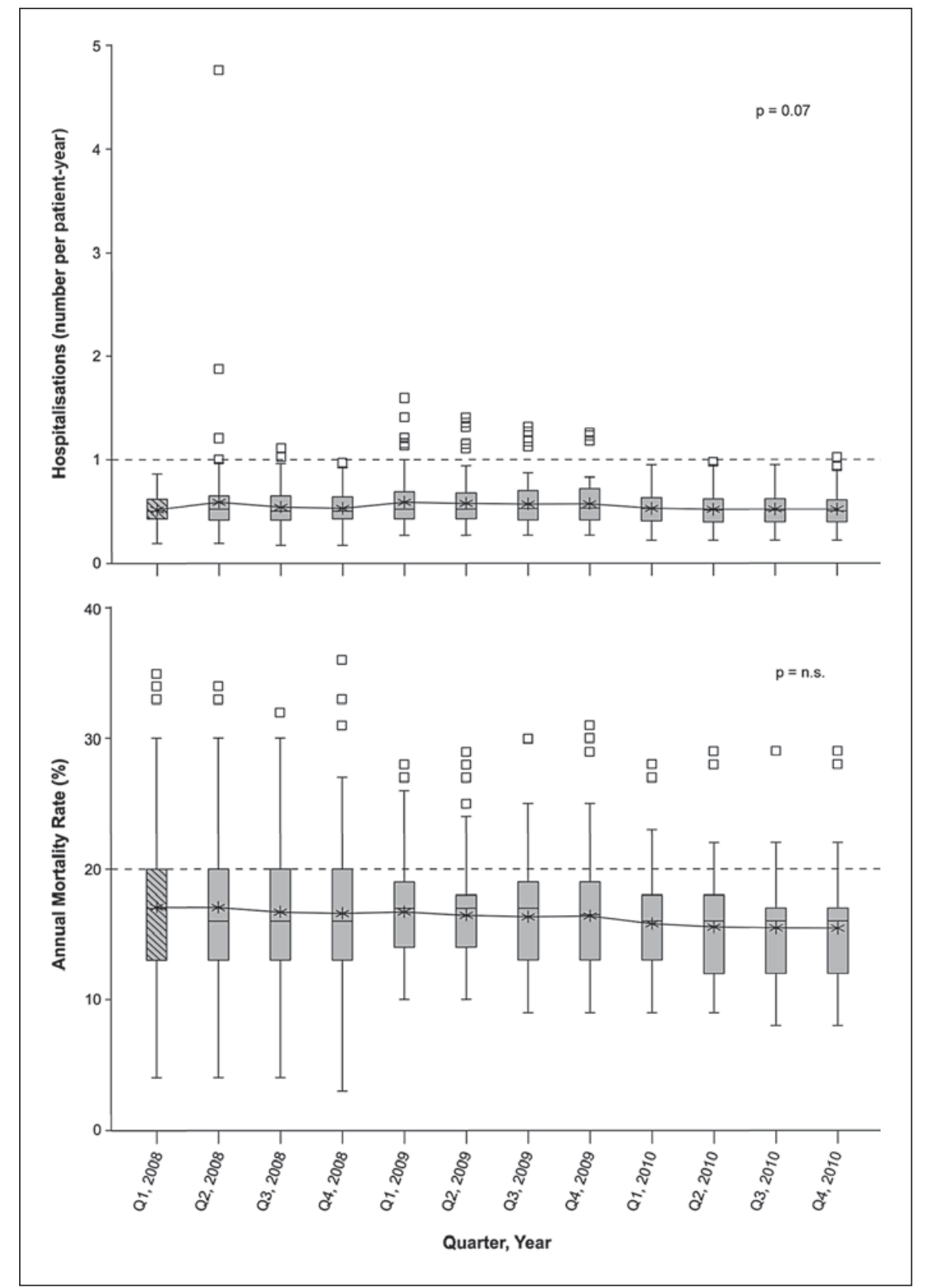

programme that was conceived, developed, implemented and, finally, tested in close cooperation with the medical staff of the clinic network. Indeed, the success or failure sof providing quality care in a capitation system lies essentially in its acceptance by the employed physicians. Throughout the medical community, a large degree of skepticism is warranted, as the issues of quality and autonomy of practice are concerns that must be taken seriously. In an environment where the provider needs to balance expenses within a fixed budget, precautions must be taken to prevent certain distortions. In particular, it must be assured that multi-morbid patients with a poor prognosis are not disadvantaged and that necessary services are not denied in order to increase margins [14, 15]. While adapting the NephroCare organization to the challenges of this new system, no significant improvements in hard outcomes (i.e. mortality, morbidity or health-related quality of life) were expected. However, 


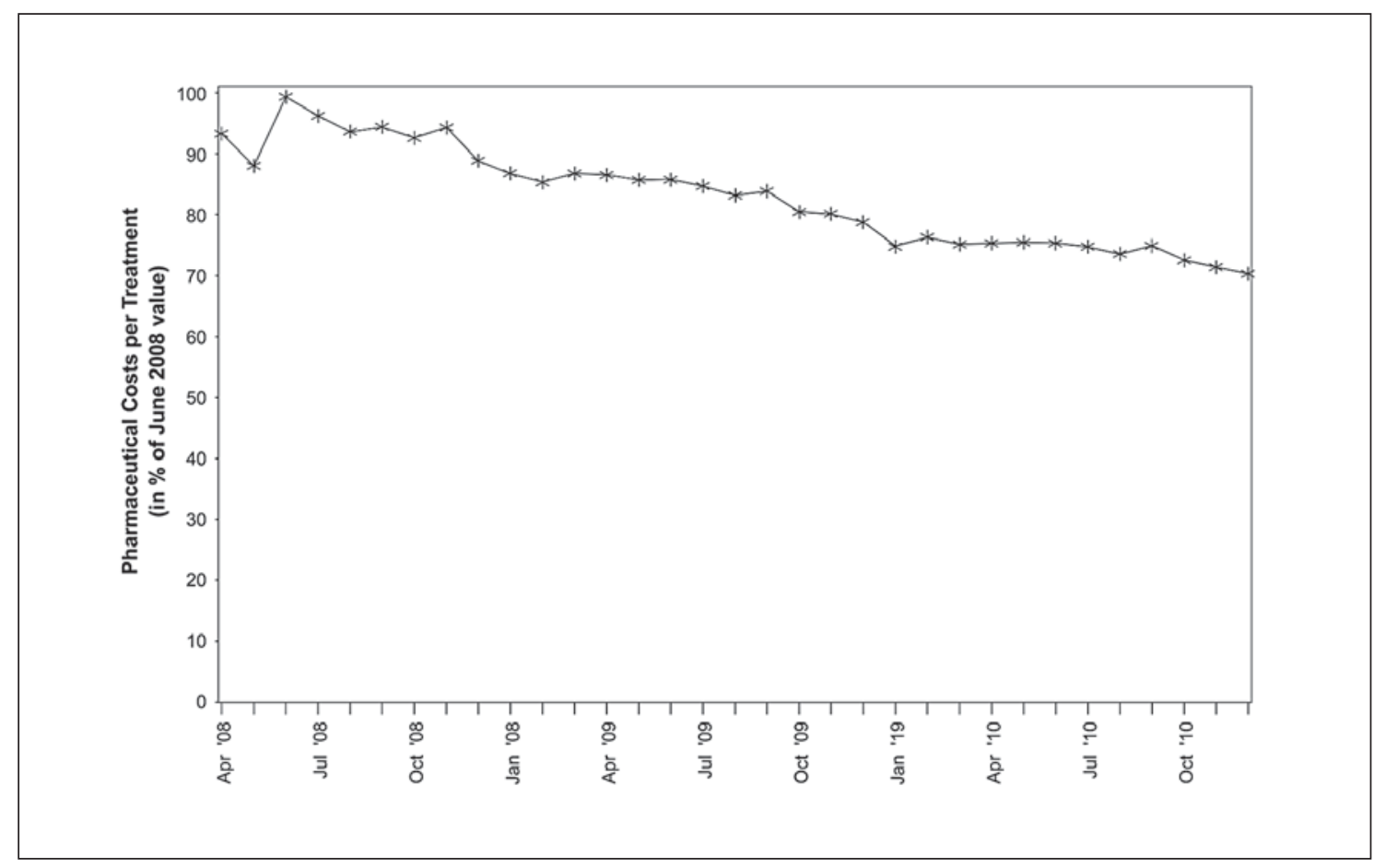

Fig. 5. Changes in monthly pharmaceutical costs per treatment averaged for all NephroCare clinics and depicted as percentage of the maximum cost (i.e. that of June 2008).

improvements in mortality and hospitalization were actually observed within a short time. These improvements were not driven by any change in patient selection, such as treating more patients with fewer comorbidities: inspection of the patient population treated by the network during the analysis time period (2008-2010) revealed an actual increase in the number of elderly patients ( $\geq 65$ years) and in the number of diabetic patients by 8 and 14\%, respectively. Nor were the improvements favorably influenced by a higher percentage of patients being treated with AVF: the number of patients dialyzed with an AVF actually decreased by $4 \%$ during the analysis time period, reaching 63\% of all patients in Q4 2010, consistent with treating an older and sicker population. Therefore, the potential to favor treatment of a healthier population that could result from capitation payment was avoided here. Expansion of reporting to the $\mathrm{MoH}$ to include such demographics could deflect this risk of the capitation system. At the same time, capitation payment puts a stop to the myth that each physician should and does apply every possible resource to an unlimited degree in every patient for even minimal potential benefit [16]. It stimulates a discussion of quality improvement that is no longer separated from cost containment efforts and patient preferences [17].

Specific features of dialysis delivery and financing make it especially amenable to a $\mathrm{P} 4 \mathrm{P}$ system for the physicians. Paying for achieving the desired level of a process indicator (e.g. hemoglobin, phosphate, Kt/V) is generally considered fair, as medical decisions have a more direct impact on such parameters than on outcomes. The risk is that this may result in a system that rewards compliance rather than performance. In this new 'target culture', physicians may become consumed with meeting laboratory quality metrics and may lose sight of the patient as a whole $[18,19]$. Furthermore, paying physicians to achieve a fixed performance target may produce little incremental benefit and serve only to reward those with already higher performance at baseline. Lacson and Hakim [19] support the option to redistribute payments from underperforming facilities to those that have achieved highquality care. Here, the philosophy adopted was to reward both top performers and those who show significant improvement in performance, paying bonuses for meeting absolute targets as well as incremental improvements. 
Insufficient funding or poorly designed incentive mechanisms can result in unintended and undesirable consequences. What we measure usually improves, but what we measure may not be relevant or may have only a vague association with the outcome we are looking for [17]. Quite often, we are measuring indicators that do not only depend on the quality of care provided by the staff of our units, and we cannot measure what we think is very important for outcomes (e.g. time devoted to patient care, easy access to hospitalization).

The introduction of VA management into the dialysis reimbursement package in Portugal in 2011 proved to be a significant challenge from both a reporting and a cost point of view. Management of VA is highly dependent on several variables; indeed, medical management is still discussing which monitoring/surveillance programs can be recommended to the clinics, as monthly measurement of access flow has serious drawbacks (e.g. poor sensitivity and specificity to predict and prevent thrombosis; failure to predict increases in access half-life; generation of many futile and expensive procedures) $[13,21,22]$. Ten indicators were proactively proposed by the dialysis provider for the monitoring of quality (table 2), but endorsement by the $\mathrm{MoH}$ is still pending.

Capitation enhances the awareness of these and other relevant issues, including data gathering capability and data analysis proficiency. After having extensively reviewed its processes, the network also observed a reduction in interclinic variance, now providing a more homogeneous, standardized and goal-directed care. Proficiency in measuring, monitoring and reporting performance improved significantly.

In conclusion, the switch to capitation payment in Portugal required intense involvement of all stakeholders, both in the preparation of the capitation package definition and in the organization and implementation of the switch. Considerable time and energy was invested in reviewing clinical practice, creating audit systems, designing an acceptable P4P system for physicians and in upgrading the IT environment. If well prepared, an improvement can be achieved over time for specified targets and for costs controllable by the physician, as observed here. Nonetheless, like the previous fee-for-service reimbursement, the system is not entirely failsafe. However, recognition of its shortcomings can instigate further improvements. Costs will remain the main driving force. At the time of submission of this manuscript, the Portuguese government, faced with a serious prevailing economic crisis, reduced the capitation payment by a further $12.5 \%$. The impact of this remains to be seen, and in a worst-case scenario could lead to abandonment of capitation payment in favor of a return to a fee-for-service reimbursement model. Each and every stakeholder must now address new challenges if the capitation payment scheme for dialysis care in Portugal is to remain viable.

\section{Acknowledgements}

We wish to give our sincerest thanks to all the people in the following participating clinics that made the realization of this project possible.

NephroCare Abrantes: Jorge Pratas; NephroCare Almada: Carlos Oliveira; NephroCare Alverca-Dialverca: Célia Gil; NephroCare Amadora: João Cruz; NephroCare Barreiro: Ilídio Rodrigues; NephroCare Beja: Carlos Pires; NephroCare Braga: Castro Henriques; NephroCare Coimbra: Pedro Maia; NephroCare Covilhã-CDBI: José Maria Montalban; NephroCare CUF/ISU: Paulo Moreira; NephroCare Entroncamento: Sequeira Andrade; NephroCare Évora: João Aniceto; NephroCare Fafe: Joaquim Pinheiro; NephroCare Faro: Pedro Neves; NephroCare Grândola: Jorge Silva; NephroCare Guarda: Tânia Sousa; NephroCare Lumiar: Pedro Ponce; NephroCare Maia: Vasco Miranda; NephroCare Montijo: Teixeira de Sousa; NephroCare Ponte da Barca: Leonidio Dias; NephroCare Portalegre: António de Sousa; NephroCare Portimão: Idalécio Bernardo; NephroCare Restelo: Augusta Gaspar; NephroCare SAMS-Lisboa: João Silva; NephroCare Santarém: Fernando Neves; NephroCare Santa Maria da Feira: João Paulo Oliveira; NephroCare Seixsal-Suldiálise: Susana Colaço; NephroCare Setúbal: José Vinhas; NephroCare Tavira: Viriato Santos; NephroCare Torres Vedras: José Galvão; NephroCare Vila Franca de Xira: Aníbal Ferreira; NephroCare Vila Nova de Gaia: Manuela Silva; NephroCare Viseu-Visodial: Rui Alves.

\section{Disclosure Statement}

All authors are employees of Fresenius Medical Care.

\begin{tabular}{|c|c|c|}
\hline References & $\begin{array}{r}\nabla_{1} \\
>_{2} \\
3 \\
>_{4}\end{array}$ & $\begin{array}{l}\text { Mongan JJ, Ferris TG, Lee TH: Options for } \\
\text { slowing the growth of health care costs. N } \\
\text { Engl J Med 2008;358:1509-1514. } \\
\text { Stopper A, Raddatz A, Grassmann A, Stuard } \\
\text { S, Menzer M, et al: Delivering quality of care } \\
\text { while managing the interests of all stake- } \\
\text { holders. Blood Purif 2011;32:323-330. } \\
\text { Ponce P, Galego V, David MI, Conceiçao N: } \\
\text { How do we react to quality indicator targets } \\
\text { and how relevant are our efforts? Port J } \\
\text { Nephrol Hypert 2010;165-171. } \\
\text { Iezzoni LI, Ayanian JZ, Bates DW, Burstin } \\
\text { HR: Paying more fairly for Medicare capi- } \\
\text { tated care. N Engl J Med 1998;339:1933- } \\
\text { 1938. }\end{array}$ \\
\hline
\end{tabular}


5 Hackbarth G, Reischauer R, Mutti A: Collective accountability for medical care - toward bundled Medicare payments. N Engl J Med 2008;359:3-5.

$\checkmark 6$ Struijs JN, Baan CA: Integrating care through bundled payments - lessons from The Netherlands. N Engl J Med 2011;364: 990-991.

7 Direcção de Serviços de Cuidados de Saúde/ Divisão de Gestão Integrada da Doença. Gestão Integrada da Doença Renal Crónica - Metas e Objectivos para Monitorização de Resultados em Diálise. Revisão. Circular Normativa No 04/DSCS/DGID, 2008.

8 Ernst and Young Company Report SP120207E sponsored by Associação Nacional de Centros de Diálise (ANADIAL): Portugal ESRD Landscape. March 2012.

$\checkmark 9$ Vanholder R, Davenport A, Hannedouche T, Kooman J, Kribben A, et al: Reimbursement of dialysis: a comparison of seven countries. J Am Soc Nephrol 2012;23:1291-1298.

10 Kirchgessner J, Perera-Chang M, Klinkner G, Soley I, Marcelli D, et al: Satisfaction with care in peritoneal dialysis patients. Kidney Int 2006;70:1325-1331.
11 Stopper A, Amato C, Gioberge S, Giordana G, Marcelli D, Gatti E: Managing complexity at dialysis service centers across Europe. Blood Purif 2007;25:77-89.

12 Steinbrook R: The end of fee-for-service medicine? Proposals for payment reform in Massachusetts. N Engl J Med 2009;361: 1036-1038.

13 Doran T, Fullwood C, Gravelle H, Reeves D, Kontopantelis E, et al: Pay-for-performance programs in family practices in the United Kingdom. N Engl J Med 2006;355:375-384.

14 Doran T, Fullwood C, Reeves D, Gravelle H, Roland M: Exclusion of patients from payfor-performance targets by English physicians. N Engl J Med 2008;359:274-284.

15 Cooke M: Cost consciousness in patient care - what is medical education's responsibility? N Engl J Med 2010;362:1253-1255.

16 Hayward RA: Performance measurement in search of a path. N Engl J Med 2007;356:951953.

17 Himmelfarb J, Berns A, Szczech L, Wesson D: Cost, quality, and value: the changing political economy of dialysis care. J Am Soc Nephrol 2007;18:2021-2027.
18 Forrest CB, Villagra VV, Pope JE: Managing the metric vs managing the patient: the physician's view of pay for performance. Am J Manag Care 2006;12:83-85

19 Lacson E Jr, Hakim RM: The 2011 ESRD prospective payment system: perspectives from Fresenius Medical Care, a large dialysis organization. Am J Kidney Dis 2011;57:547549

20 Paulson WD, Work J: Controversial vascular access surveillance mandate. Semin Dial 2010;23:92-94.

21 Ram SJ, Nassar R, Work J, Abreo K, Dossabhoy NR, Paulson WD: Risk of hemodialysis graft thrombosis: analysis of monthly flow surveillance. Am J Kidney Dis 2008;52:930938.

22 Chang CJ, Ko PJ, Hsu LA, Ko YS, Ko YL, et al: Highly increased cell proliferation activity in the restenotic hemodialysis vascular access after percutaneous transluminal angioplasty: implication in prevention of restenosis. Am J Kidney Dis 2004;43:74-84. 